\title{
"Lots of People Pretend..." Shame Conflicts in an Age of Digital Self-presentation and Point-scoring
}

\author{
Vera KING | ORCID: 0000-0003-3901-1068 \\ Professor, Goethe-University \& Sigmund-Freud-Institute Frankfurt, \\ Frankfurt/M., Germany \\ King@soz.uni-frankfurt.de
}

\begin{abstract}
The digital media have spawned new cultures of self-revelation and hence new conflicts. The downside of self-presentation, comparison, and point-scoring is identifiable in the emergence of shame conflicts that are progressively taking on new meanings. This article examines (a) the significance and transformation of shame in the context of digitization and (b) the psychosocial consequences of shifts in the boundaries between public and private manifesting themselves in the contemporary digital world. In particular, it examines changing functions, ambivalences, and affective pitfalls of selfpresentation in the socialization processes of adolescence. The article is based on empirical studies.
\end{abstract}

\section{Keywords}

digital shame - youth - digitization - social media dynamics - shame conflicts externalization

\section{$1 \quad$ Introduction}

This article contends that digital modernity brings forth new shame conflicts and that these are particularly striking in the socialization processes taking place in adolescence. The digital media have spawned new cultures of selfrevelation. The downside of self-presentation, comparison, and point-scoring is identifiable in the emergence of shame conflicts that are progressively taking 
on new meanings. Here we examine the significance and transformation of shame in the context of digitization, more particularly in the psychosocial and psychological consequences of the shifts in the boundaries between public and private manifesting themselves in the contemporary digital world. Of central concern are the changing functions, ambivalences, and affective pitfalls of self-presentation in adolescence.

Accordingly, the article is less concerned with normative observations than with (a) the analysis of the psychic significance of self-presentation and communication in digital worlds and (b) the associated transformations of shame in digitized relationships. The focus is not on the frequently discussed phenomenon of lower shame thresholds, i.e. revealing oneself and sharing the intimate details of one's life publicly on the web. Instead, we home in on (a) the more crucial transformations in configurations of shame brought about by changes in the meaning of the way others see/look at us in the context of the digitization of communication and life practices, and (b) associated changes in the relations between self and other in a communicative context in which the gaze of the other is directed, both actually and figuratively, at an image of the self that has been generated through the use of media. Shame conflicts materialize at the interface between self and other, self and world and are also the result of the greatly enlarged scope of comparison between the one and the many.

After a review of theoretical approaches to shame and the dynamics of digital self-optimization and shame regulation, we discuss the significance of digital media in adolescence and the dynamics of self-optimization and shame regulation in adolescents. On the basis of comments by contemporary adolescents on the significance of social networks and their own digital selfpresentation, we identify mechanisms employed in dealing with the gaze of the other on the internet, be it imagined, projected or denied. Examples of these phenomena are taken from a qualitative-reconstructive pilot study. The article ends with conclusions on public conflicts in digital worlds.

The self is constructed through the gaze of the other, shame derives from the awareness of this relation. Sartre (1943) describes this experience trenchantly in Being and Nothingness, where he writes: "Shame is a unitary apprehension with three dimensions: I am ashamed of myself before the Other" (pp. 289). Seidler (2000) extends Sartre's constellation of shame in his book on the analysis and psychoanalysis of shame. In his conception of shame and alterity, the 
author distinguishes between three structural levels of shame depending on whether a) someone "is able to be genuinely self-reflective", b) self-reflection "requires the real presence of an external observer", or c) is "shamelessly 'naïve' vis-à-vis" the gaze of the other (Seidler, 2014, pp. 827). The capacity for shame also reflects the degree of structural development the psyche has attained. Shame may be a response to the experience of objectification or take on a distressing or even pathological character. But in Seidler's perspective it is not merely a negative phenomenon, not merely a potent and meaningful intrapsychic affect with a negative impact on our sense of self-worth. It also serves to protect us from, and bind us to, others (Scheff, 200o).

Shame, in other words, performs two operations simultaneously. Like the two sides of a coin, it is both a model of psychological development and the construction of subjectivity. It is "in others' eyes" that the "I" recognizes itself and its value and becomes aware of its own self. This fundamental constellation of self-evolution in the mirror of, and through the resonance from, the other (Winnicott, 1965) can be formulated in various theoretical positions emphasizing different aspects of the process - object relations theory, the findings of infant research, and also attachment and mentalization theory, intersubjectivity and recognition theory. According to Kohut (1971), the self delineates itself ideally in the mother's shining eyes (pp. 141). The gaze of the other is indeed a mirror of the self, but it is more than simply a reflection. New meaning is continually produced in the interaction and mutual relationship between self and other. Shame is a developmental-psychological aspect of this process. It points to the dialectic of success in proving one's worth/status and the potential for failure in the eyes of the significant other. At the same time, it reveals the self's dependence on the related and affirming other and on the constructive relational experiences out of which the developing childhood self emerges and the adult self draws its psychic energy.

The possibility of shame, the potential to feel ashamed, is thus a constitutive and indispensable part of a dependency constellation from which we cannot escape. Without the other's gaze, the child's world remains empty and its psychological development is impeded. This is how the Subject establishes itself in the eyes and in the gaze of the other, the one who "sees and recognizes", who provides affection and affirmation. For the self, this gaze involves important emotional consequences. Love and appreciation produce balanced satisfaction with oneself and a sense of pride, while indifference and rejection produce insecurity and a fearful, unstable sense of self, resulting in some cases in compensatory attempts to achieve independence through increased selfcenteredness or exaggerated feelings of grandiosity. Like pride, shame is an 
affect closely connected to narcissism, to the sense of self, and to self-esteem at a basal level (Hilgers, 2012).

Sociological approaches indicate that the experience of shame is related to social conditions. When, why, and how shame is experienced or triggered is dependent on a number of different cultural and historical circumstances (Neckel \& Straub, 1991, 2019), as well as on the social and psychological constellations of self and other. With regard to the cultural meanings of shame, it was long held that not shame but guilt is the affect typically connected with individualistic capitalist societies. Shame, it was thought, plays a regulatory role in societies where individuals can be branded as failures and ostracized if they lose face and forfeit their honor. More recently, however, it has increasingly been suggested that shame has regained its influence in late modernity, in present-day societies where individuals gearing their self-image to performance, self-improvement, and the "sky's the limit" mentality are constantly confronted with the tension between optimization norms, self, and ideal (Ehrenberg, 2009). Our contention is that the idea and meaning of (the gaze of) the other has been changing in the wake of digitization, lending a different quality to the phenomenon of shame.

\section{3}

\section{Self-optimization and Shame}

Given all the new guises in which they manifest themselves, self-presentation and public visibility are rapidly gaining significance. For many, impression management and unremitting comparison with the digital and/or media presence of others have become second nature and are frequently felt to be indispensable. To assert oneself, one needs attention. To improve, or even just to maintain, one's status and to jockey successfully for positions, it is essential to establish a media contour, to test oneself against others, and to face up to evaluation by those others. In the course of all this, people active in this sector will usually turn into specialists in self-presentation, comparison, and pointscoring (Vormbusch, 2012).

This applies not only to the services and consumption sector but also to the presentation of achievements in job contexts where salary, promotion prospects, recognition, and commissions are geared to sales figures, quotas, rankings, etc. Here success, achievement, and standing depend on assessments and scores that are good enough to be "a credit to anyone" and are visible in the digital world for many more people than was formerly the case (Mau, 2017). If one is not to fall behind in the great optimization contest, the good scores 
required are very often synonymous with high (or higher) figures, at all events with a better showing than competitors can point to.

Bröckling (2015) describes the categorical imperative of our times as a maxim with the invocation "Be entrepreneurial!" Every single person is called upon to think in terms of the logic of the "entrepreneurial self" (ibid.), to focus on lifelong profit, customer satisfaction, and success, and to act flexibly and be prepared to take risks (Bröckling, 2019). This new mode is the result of permanent competition and it continually demands ongoing, enhanced, and ultimately never-ending optimization efforts (King et al., 2019). In this context, optimization means an unremitting orientation to improvement, to pushing back frontiers and transcending boundaries, to the creation of relationships (with others and with oneself) within the logic of investment and anticipated returns, and to keeping our options open (in case returns might be higher elsewhere) (King et al., 2019a, 2020). Yet no amount of effort is able to quell the fear of failure: "Because one can assert one's position only for the moment and only in relation to one's competitors, no one can simply rest on their achievements. Today's recipe for success is tomorrow's path to ruin." (Bröckling, 2015, pp. 10).

As regards optimization via digital point-scoring, we find that complying with such norms - i.e. gearing one's overall attitude and approach to good figures and high scores in the social media - may be ambivalent and have paradoxical consequences. One example is the substitution of quantity for quality, as has become apparent from the findings of the transdisciplinary research project "Measured Lives" (King et al., 2019b) ${ }^{1}$. Men and women may attempt

1 In the transdisciplinary research project 'Measured Lives. Productive and counter-productive consequences of quantification in societies with digital optimization based on figures', scholars and scientists in Frankfurt, Jena, and Berlin investigate how measurement, scoring, and comparison are increasingly gaining ground in everyday life. The project has been funded by the Volkswagen Foundation since 2018 under the heading "Key Topics in Science and Society". The investigations inquire into the productive and counter-productive consequences bound up with an "orientation to figures" and life-measurement. In their endeavors, the researchers involved cast light above all on the intersubjective and psychic meanings and significances of quantitative optimization in organizational contexts and in the way individuals lead their lives.

In attempting to determine the complex concatenations between different strata of society, the researchers focus on different factors. The Jena section of the project, headed by Hartmut Rosa, uses interviews with experts to home in on the orientation to figures in the practices and modes of interaction displayed by professional organizations. The Frankfurt section, headed by Vera King, analyzes narrative interviews to investigate the significance of digital quantification for the handling of relations in the social media. The Berlin section, headed by Benigna Gerisch, focuses on varieties of body-related self-measurement, not least those related to pathological instances of quantification in body-practice. These qualitative 
subjectively to distance themselves from these phenomena, but in many cases it is hardly possible to escape them, as Ms S. (36) recounts in connection with posting things on the social media:

When all my friends give me likes, it means they find my picture appealing or love what I've written. But sometimes I get really scared. Maybe they don't like what I've written, maybe they're saying: 'What's the point of it? Why is she revealing herself like that?' That gets me worried. It has to be really good, one hundred percent, before I post anything. Then I think: 'Why am I doing this?' But I still do it. That means I can't post what I really want to post, I post the things that I think most people will like.

Ms S. is aware that she is conforming with other people's expectations, and she questions what she is doing, but she is still unable to stop herself (ibid.). She is ashamed of complying with this norm, but she would be even more ashamed if she got bad scores, so she does her best to optimize her digital selfexpression. Shame is therefore regulated externally by the avoidance of rejection rather than by self-criticism. And this kind of involvement is found not only in adults but also, and especially, in adolescents, with serious repercussions on their development and socialization. ${ }^{2}$

From empirical investigations on the digital behavior of adolescents, Schachtner et al. (2016) have singled out a number of typical functions that appeal to media users. Alongside entertainment and contact, they home in on typically adolescent issues, such as digitally enhanced opportunities for selfdisplay or (playful) boundary transgression in the digital media, as a way of coping with the transition from childhood to adolescence or adulthood.

For adolescents, sharing self-presented images of oneself with others is eminently important. It has a variety of functions and is frequently resorted to

investigations are supplemented by a survey based on a joint questionnaire elaborated by all three sections of the project (cf. King et al., 2019b).

2 Cf. also Baym, 2010; Voderer et al., 2016; Zizek, 2017; Deh \& Glođović, 2018; Krüger, 2019 and others. 
for purposes of adolescent self-ascertainment. As we have seen, sharing is one of the basic principles of digital connectivity and attention. When someone posts a selfie on the web or shares a picture of what they're eating, the image proliferates directly and simultaneously. Rubinstein suggests that the most important feature of a selfie is its immediate shareability. Taking a picture and sharing it are closely connected, linking two messages: "This is me!" and "This is now!" (ibid., 2014), messages that are particularly appealing and significant for adolescents.

Accordingly, these performative acts so popular with present-day youngsters can be understood as experimental adolescent self-creation in ever new guises. What it boils down to is a game with the second birth. Exposing oneself to others can thus approximate the functions performed by adolescent initiation rites (cf. King, 2013, pp. 271.).

At the same time, we can safely assume that in a media world where everything is invariably available and present, the contours of being-there and notbeing-there and of beginning and end will tend to be blurred. If things come and go so quickly but are at the same time somehow saved and "there", if presence and absence no longer mean what they used to mean, then these new constellations will have repercussions on our relations with the world, with others, with our (and others') bodies.

To illustrate this, I refer at this point to a number of interviews with adolescents that I carried out in the framework of teaching-research projects in Hamburg and Frankfurt and as part of a subsequent pilot study on adolescent selfpresentation in the social media, conducted in conjunction with Susanne Benzel and others. The project was designed as a qualitative-reconstructive pilot study. Part-focused interviews were conducted with male and female adolescents aged $16-22$ years.

\section{Methods and Design}

Generally speaking, the given context calls for studies dedicated to the way individuals cope with the tension between showing and concealing, between the pressure to adapt and the bid for optimization. Accordingly, we chose a qualitative-reconstructive approach. This approach necessitates not only a record of the 'self-interpretations' - i.e. explicit self-understanding - provided by the interviewees, but also a methodical reconstruction of latent meaning and possible differences between subjective attitudes and actual practice. Methodological approaches must therefore be capable of capturing latent contradictions or paradoxes in digital self-representation practices and the 
circumstances conditioning the attempts to cope with them. Accordingly, the evaluation of the interviews was carried out with the help of text-analytic approaches (Zizek, 2017; King et al., 2013) taking scenic aspects into account (ibid.). In the first part, the interviewees were asked to talk about their communication practices, both online and offline; in the second they were asked to enlarge on one image that they had shared online. Image-based self- and bodyrepresentations were evaluated by means of segment analysis (Breckner, 2010) and referred to the textual meanings in each case.

In the final sub-section of the study, 20 interviews were conducted with 13 young women and seven young men. In both the preceding Hamburg and Frankfurt sub-sections, about 20 interviews also took place (cf. King, 2018; Benzel \& King, 2019). The interviewers themselves were young men and women in their early 20 , a strategy designed to facilitate open discussion.

In the course of our pilot study on young people's self-presentation, it became apparent how much time and effort youngsters (including adolescents) invest in perfecting their digital image. The researchers were particularly interested in the relation between online and offline self-presentation in the eyes of these youngsters. To cast light on the way digitization both extends and standardizes the scope for communication, they investigated presentation and visualization strategies and set them in relation to topics associated specifically with adolescent development.

The findings indicate that interaction success in the social media is extremely important and that the aim of increasing scores often becomes an end itself:

...You get notified on your phone or through Facebook - telling you about - messages - you know how many likes you get - a message for a like or a comment - and, of course, you follow that ... so ... 'cause you just always go to Messages and, well ... of course you look at the photo to see how many likes it has. (Tom, 16)

Self-presentation, then, must always focus on drawing maximum attention to oneself and showing oneself in the best possible light. This is doubly true, we might add, in digital contexts. 'Successful' digital self-presentation must be permanently controlled and renewed. In a teaching-research project associated with a seminar at the University of Hamburg, interviews with adolescents 
were designed to find out what it meant to them to post images of themselves on social networks. The results of these explorations underscore the degree to which precisely this logic of optimization and the figure of the entrepreneurial self were implemented in the young people's digital self-presentation practices.

The adolescents maintained, organized, and fine-tuned their self-presentations with painstaking attention to detail, like an entrepreneur keeping an eye on his daily profits. They looked precisely to see which images were received by viewers and how, through the use of particular hashtags, technical possibilities, and general finesse, they managed to artificially raise the number of likes (if you like me, I'll like you). New "products", i.e. images of themselves, were subjected to constant testing and evaluation. There was also a continual process of optimization in their self-presentation, designed to "sustain" an audience, i.e. keep the attention of others, increase their numbers, and win their loyalty. Here is one adolescent (Bianca) thinking about what would happen if she stopped improving her presentation on the web and no longer posted photos to increase the number of likes or followers:

Interviewer: What do you think would happen if you were to suddenly stop posting photos?

Bianca: Well, if I suddenly stopped posting any more photos at all, the first thing that would happen is that I would lose all my followers (laughs).

I: Oh no (laughs).

B: No - that's bad - I'd lose all of my followers right off the bat.

I: And having followers is extremely important, right, that you have lots of them?

B: Yes.

I: Why?

B: I don't know, I mean, I don't really know. ... Most followers aren't even people I know. They aren't even friends of mine. Yeah, I, like, actually think followers are only important so, well, so they just see what kind of photos I have and so on. I don't know.

I: But you would probably be sad if, let's say, half of your followers canceled their subscription suddenly, right?

B: I would be really sad!... Yeah, that would be a real drag, after all that hard work. I say hard work, but -

I: Yeah. 
B: - It's really hard work to get that many followers.

These responses illustrate the extent to which the optimization efforts of the "entrepreneurial self" must be permanently sustained in a very concrete and practical sense. While this entrepreneurial logic is by no means limited to the digital sphere, it is strikingly clear how much this work in the digital network epitomizes the entrepreneurial ductus, the imperative of constant improvement and performance, and how, precisely by this means, adolescents are trained and socialized, almost to perfection, in the relevant forms of entrepreneurial behavior. At the same time - remember, the focus is on adolescents their vulnerability is palpable. Their uncertainty, not to say self-doubt, is something that can hardly escape the glaring light of this presentation marketplace. It manifests itself, for example, in the question: "What would happen if the others saw the real me?"

Some of the teenagers interviewed stated that they regulated their feelings of self-worth by posting images of themselves:

When I'm not doing well, I post a nice photo on Facebook and if it gets a good response and lots of people like it, it makes me feel better. Of course, the opposite is true if something goes wrong.

Here are some excerpts from the interviews with these young men and women. First Anna (18) responding to the interviewer's question: "What do you think people in general, or perhaps your friends, want to achieve by posting images in social networks?"

A: Well, that other people have some kind of idea who you are. And somehow you make an impression on them or something. And I think lots of people ... when they post a photo, most likely want to show how good they look - I mean, no one actually posts a photo they look terrible in. Actually, I think that would be really cool, but no one ever does it. I think they want to achieve, to create an image of themselves, so that others think of them like that..." (Anna, 18).

$\mathrm{J}$ : Lots of people pretend to be something, maybe to feel better about themselves, or they edit [the photos] a lot. I mean, I know a few people who really do a lot of that ... (Jule, 18). 
T: Every day a new photo - just to get those likes ... (Tom, 16).

At the same time, there is shame about the dependence of an individual's self-worth on these practices, although - in the majority of cases - it is clear that we are dealing with the creation of appearances, a construction. Tony:

And that's just somehow, in some way, totally stupid and I think, too, that there is too much of that ... I mean ... I just don't think it's good that ... well, on Facebook everything is just so extremely faked and extremely ... embellished, and that ... I just don't like it.

Insecurity creates needs, or, more precisely, it makes neediness continually reproduce itself. The unambiguous experience of successfully proving one's worth or one's mettle in the presence of others, with others watching, is lost in the digital vagueness, virtuality, and uncertainty of the online relationship between self and other. The functions of failure and success lose their foundations, as it were. Failure is not failure; it was probably just the wrong image of myself. Confirmation is not confirmation; it is not genuine recognition, since it was only an image and not my real face, as we see in the thoughts of the young woman whose words are quoted in the title of this essay: "If you show your real face, you'll lose 10, ooo followers."

A great deal of the "hard work" involved in obtaining good scores has to do with concealment. So much embellishment, improvement, and filtering goes on that the "real face" finally disappears behind the optimized version. At the same time, there is a species of shame at the dependence of self-worth on these practices, especially when the person in question realizes that the final product is, to all intents and purposes, a fake:

In some ways it's really stupid, there's too much of it ... I don't think it's good that on Facebook everything's so extreme, so glamorized. ... I just don't think it's good" (cf. King, 2017, 2018).

In a variety of ways, shame turns out to be the downside of self-revelation, comparison, and rivalry. Shame materializes if one visibly cuts a poor figure, has only a few likes and followers, poor scores and evaluations. To avoid this happening, self-presentation is optimized even more (according to the youngsters interviewed, "everyone" does it). But shame can also result from the knowledge or feeling that in reality one is nothing like the digital image of oneself, that conceivably one would lose "10,000 followers" if one were to show one's "real face." And another source of shame is the vivid realization of one's 
dependence on recognition for one's efforts and on the response from the digital audience. Thus shame conflicts, both social and psychological, gain significance.

We said at the outset that, in practical and dynamic terms, digital shame conflicts also represent a struggle between self-revelation and self-concealment, a tension between the urge to present oneself and a desire to hide or disguise oneself to the point of invisibility (may the ground open up and swallow me!) or the fear of social demise on grounds of a failure perceived as existential (losing face, not being able to show one's face). In affective terms, shame operates like a flood-gate (visible in shame-faced blushing, etc.). In our subjective experience, shame goes coursing through our veins as an expression of failed fantasies of success, a lust for power stymied, pride cast down, or omnipotence thwarted, but also, not least, when physical or emotional intimacies are dragged out into the light of day. Shame affects are guardians of social and individual norms all the way up to the integrity of the affective and corporeal self. Shame conflicts, by contrast, can be inhibiting in their effects and thus represent a hindrance to vitality, love, and life.

Not least, shame and shaming are ingredients of social order and hierarchy and can thus be an expression of social inequality (status shame, being ashamed of poverty, failure, clothing, looks, poor performance, poor scores...). The findings illustrate that, in this sense, digital shame conflicts belong to the sphere of social conflict tension in general. And they are necessarily exacerbated to the extent that revelation and skillful presentation as well as clever concealment become indispensable conditions for success, social recognition, and belonging.

Digital technologies create new conditions for optimizing lifestyles in general and for adolescent socialization and development in particular. In this sense, the omnipresence, individual addressability, and technical refinement of the measurement processes are structurally momentous and hardly anyone can escape them, specifically in connection with the cultural, or simply economic, pressure to adapt, which takes place in different ways. And inevitably momentous is the unmanageable enlargement of the scope of comparison with the many, who thus change into a legion of significant others. When digital measurement results (be they fitness data, sales or follower numbers, credit points in the language-learning app, etc.) are continuously collected, stored, and compared 'with all the others,' this engenders a new cultural matrix of permanent comparison and competition. A further structurally salient effect is 
the strong dominance of instrumental logic in relation to oneself, others and the body, a logic created by measuring optimization.

As the examples show, digitization has changed the relevance of selfpresentation and the significance of other people's verdicts, giving shame a new quality and a new significance. Digital forms of communication cause physical and communicative presence to drift further apart (we need only recall the absorbed gaze of the physically present other preoccupied with digital information and the fragmentation of attention associated with it; cf. Gergen, 2002; Turkle, 2011; King, 2018). At the same time, the "eyes of others" contemplating pictures of the self on the media have gained a new significance. Accordingly, both adults and adolescents operating in digital worlds are confronted by challenges that are sometimes familiar, sometimes new, and at all events typical. Chief among them is the tension between too much and too little, not least in connection with self-presentation (here the interviewees were quick to criticize others for showing too much of themselves).

In all this, publicly visible status levels and comparisons with others are experienced partly as pleasurable rivalry, as a sporting contest, partly as a stressful nuisance due to the fear of ignominy bound up with status loss. In many cases, the point at issue is also the tension between conformity and difference, with the anonymous gaze of the digital other(s) and the conformity pressure bound up with it encouraging external orientations (pandering to others to score points) that the protagonists are then promptly ashamed of.

Against this background, shame conflicts take on a whole array of meanings associated with the dynamics of self-revelation, point-scoring, and comparison. The fear of shame caused by social exclusion (status loss or ostracism) appears to be increasing, whereas the shame involved in turning away from others physically present and interrupting face-to-face communication seems to be on the wane. New species of shame materialize due to dependence on digital practices and sensitivity to echoes from the web that is sometimes felt to be addictive. Such dependence can become especially distressing if the digital gaze of others is solicited to satisfy longings (recognition, affection, attachment) that cannot be sufficiently fulfilled by physically present others.

Not least, shame derives from the inadequacy of the digital self. The feeling that the digitally presented self would not stand up to a test of its resilience is at the same time held to be unavoidable. Many appear to feel that they have to go through with it, otherwise success will become unattainable. Thus this species of shame is a consequence of the infinitely broadened horizon of comparison with the many, the digitally significant others. For if digital self-presentation is constantly evaluated, assessed, saved, and brought in line with "all the others", then a new cultural matrix of the relation between self and others will materialize, with all the ambiguities and contradictions we 
have referred to. Thus digital modernity spawns new shame conflicts that have particular consequences in adolescence. In addition to these qualitative approaches, quantitative and longitudinal studies that differentiate the change of shame in digital worlds for different age groups would also be helpful for further studies.

\section{References}

Baym, Nancy K. (2010). Personal Connections in the Digital Age. New York: Polity Press. Benzel, S. \& King V. (2019). Körperzeiten - Körperpraxen. Neue Herausforderungen der Adoleszenz und ihre Ausdrucksformen in Social Media-Selbstdarstellungen. Das zeitpolitische Magazin 34, Jg 16, pp. 4-7.

Breckner, Roswitha (2010). Sozialtheorie des Bildes. Zur interpretativen Analyse von Bildern und Fotografien. Bielefeld: Transcript.

Bröckling, Ulrich (2015). The Entrepreneurial Self: Fabricating a New Type of Subject. New York: SAGE Publications Ltd.

Bröckling, U. (2019). The subject in the marketplace, the subject as a marketplace. In: King, V., Gerisch, B. \& Rosa, H. (Eds.) Lost in Perfection. Impacts of Optimisation on Culture and Psyche (pp. 24-35), London: New York Routledge.

Deh, D. \& Glođović, D. (2018). The Construction of Identity in Digital Space. Art + Media Journal of Art \& Media Studies, Issue 16, pp. 101-111.

Ehrenberg, Alain (2009). The Weariness of the Self: Diagnosing the History of Depression in the Contemporary Age. North Yorkshire: Combined Academic Publ.

Gergen, K. (2002). The Challenge of Absent Presence. In Katz, J. E. \& Aakhus, M. (Eds.), Perpetual Contact: Mobile Communication, Private Talk, Public Performance (pp. 227-241). Cambridge: Cambridge University Press.

Hell, Daniel (2018). Lob der Scham. Gießen: Psychosozial.

Hilgers, Micha (2012). Scham. Gesichter eines Affekts. Göttingen: Vandenhoeck \& Ruprecht.

King, V. (2017). "If you show your real face, you'll lose 10 ooo followers" - The Gaze of the Other and Transformations of Shame in Digitalized Relationships. CM: Communication and Media Vol 11, No 38 (2016). DOI: 10.5937/comman12-11504.

King, V. (2018). Geteilte Aufmerksamkeit. Kultureller Wandel und psychische Entwicklung in Zeiten der Digitalisierung. Psyche- $Z$ Psychoanal 72, 2018, pp. 640-665. DoI: 10.21706/ps-72-8-640.

King, V., Koller, H.-C. \& Zölch, J. (2013). Dealing with Discrimination and the Struggle for Social Advancement in Migrant Families: Theoretical and Methodological Aspects of a Study on Adolescent Generational Dynamics in Turkish Migrant Families Subjected to Marginalization. International Journal of Conflict and Violence. IJCV: Vol. 7 (1), pp. 121-134. 
King, V., Gerisch, B. \& Rosa, H. (2019a). 'Lost in Perfection' - Ideals and Performances. In King, V., Gerisch, B. \& Rosa, H. (Eds.), 'Lost in Perfection'. Impacts of Optimisation on Culture and Psyche. (pp. 1-10). London, New York: Routledge.

King, V., Gerisch, B., Rosa H., Schreiber, J., Findeis, Ch., Lindner D., Salfeld B., Schlichting M., Stenger, M. \& Voigt, St. (2019b). Psychische Bedeutungen des digitalen Messens, Zählens und Vergleichens. Psyche- Z Psychoanal, 2019, 9/10.

King, V., Gerisch, B. \& Schreiber, J. (2020). “...to really have everything completely perfect": On the Psychodynamics of Contemporary Forms of Body Optimization, Psychoanalytic Psychology, 37(2), pp. 148-157. DOI: 10.1037/papoooo287.

Kohut, Heinz (1971). The Analysis of the Self. New York: International University Press.

Krüger, St. (2019). The authoritarian dimension in digital self-tracking: containment, commodification, subjugation. In: In King, V., Gerisch, B. \& Rosa, H. (Eds.), 'Lost in Perfection. Impacts of Optimisation on Culture and Psyche. (pp. 85-104). London, New York: Routledge.

Mau, Steffen. (2017). Das metrische Wir. Berlin: Suhrkamp.

Neckel, Sighard (1994). Status und Scham. Frankfurt a. M.: Campus.

Sartre, Jean-Paul (1943). Lêtre et le néant. Saint-Amand: Gallimard.

Scheff, T. J. (2000). Shame and the Social Bond: A Sociological Theory. In Sociological Theory, 18: (pp 84-99). DoI:10.1111/0735-2751.00089.

Seidler, G. H. (2000). In Others' Eyes. An Analysis of Shame. Foreword by Léon Wurmser. Preface by Otto F. Kernberg. Madison: Conn International Universities Press.

Seidler, G. H. (2014). Scham. In Mertens, v. W. (Ed), Handbuch psychoanalytischer Grundbegriffe (pp. 827-830). 4. erw. Aufl., Stuttgart: Kohlhammer.

Straub, J. (2019). Rationalising life by means of self-optimisation: the obsessive compulsive excess of Gustav Grossmann. A striking example for the rationalistic bookkeeper-personality. In King, V., Gerisch, B. \& Rosa, H. (Eds.), 'Lost in Perfection'. Impacts of 'Optimisation on Culture and Psyche. (pp. 153-188). London, New York: Routledge.

Tiedemann, Jens L. (2013). Scham. Gießen: Psychosozial.

Turkle, Sherry (2011). Alone Together. New York: Basic Books.

Voderer, P., Kroemer, N. \& Schneider, F. (2016). Permanently Online - Permanently Connected: Explorations into University Students' Use of Social Media and Mobile Smart Devices. Computers. Human Behavior, 63, pp. 694-703. DOI: 10.1016/j .chb.2016.05.085.

Vormbusch, Uwe (2012). Die Herrschaft der Zahlen. Frankfurt/M.: Campus.

Winnicott, Donald W. (1965). The Maturational Processes and the Facilitating Environment. Studies in the Theory of Emotional Development. New York: International Universities Press.

Zizek, B. (2017). Digital socialization? An exploratory sequential analysis of anonymous adolescent internet-social interaction. Hum Dev 6o, pp. 203-232. 